\title{
Partial stem and leaf resistance against the fungal pathogen Botrytis cinerea in wild relatives of tomato
}

\author{
Arjen ten Have $\cdot$ Ralph van Berloo $\cdot$ \\ Pim Lindhout · Jan A. L. van Kan
}

Received: 12 July 2006/Revised: 20 October 2006/ Accepted: 2 November 2006 /

Published online: 23 December 2006

(C) KPNV 2006

\begin{abstract}
Tomato (Solanum lycopersicum) is one of many greenhouse crops that can be infected by the necrotrophic ascomycete Botrytis
\end{abstract}

Electronic supplementary material Supplementary material is available in the online version of this article at http://dx.doi.org/10.1007/s10658-006-9081-9 and is accessible for authorized users.

A. ten Have ·. A. L. van Kan ( ()

Laboratory of Phytopathology, Wageningen

University, Binnenhaven 5, 6709 PD Wageningen,

The Netherlands

e-mail: jan.vankan@wur.nl

R. van Berloo · P. Lindhout

Laboratory of Plant Breeding, Wageningen

University, Droevendaalsesteeg 1, P.O. Box 386, 6700

AJ Wageningen, The Netherlands

Present Address:

A. ten Have

Instituto de Investigaciones Biologicas, Facultad de

Ciencias Exactas y Naturales, Universidad Nacional

de Mar del Plata, cc 1245, 7600 Mar del Plata,

Argentina

e-mail: atenhave@mdp.edu.ar

\section{Present Address:}

P. Lindhout

De Ruiter Seeds, Leeuwenhoekweg 52, 2661 CZ

Bergschenhoek, The Netherlands

e-mail: pim.lindhout@deruiterseeds.com

R. van Berloo

e-mail: ralph.vanberloo@wur.nl cinerea. Commercial cultivation of tomato is hampered by the lack of resistance. Quantitative resistance has been reported in wild tomato relatives, mostly based on leaf assays. We aimed to identify wild tomato relatives with resistance to $B$. cinerea based on quantitative assays both on leaves and stem segments, monitoring infection frequency and disease expansion rate as parameters. A quantitative tomato stem segment assay was developed. This stem assay and a previously described leaf assay were used to screen a collection of 22 Solanum accessions. Significant differences in disease parameters were observed among accessions. Resistance to $B$. cinerea was observed in a number of wild Solanum species, including accessions of S. chilense, S. habrochaites and S. neorickii, both in the leaf assay and the stem segment assay. A number of resistant and susceptible accessions were evaluated as adult plants under greenhouse conditions. The data obtained in greenhouse assays confirmed the leaf and stem disease data. The expression of several defence-related genes was studied in a subset of accessions. There was no apparent correlation between the expression levels of the genes tested and the quantitative resistance level to B. cinerea.

Keywords Grey mould - Solanum $\cdot$ Quantitative resistance 


$\begin{array}{ll}\text { Abbreviations } \\ \text { ANOVA } & \text { Analysis of Variance } \\ \text { cv. } & \text { cultivar } \\ \text { HPI } & \text { hours post-inoculation } \\ \text { LIF } & \text { leaf infection frequency } \\ \text { SIF } & \text { stem infection frequency } \\ \text { RLIF } & \text { relative leaf infection frequency } \\ \text { RSIF } & \text { relative stem infection frequency } \\ \text { LLER } & \text { leaf lesion expansion rate } \\ \text { RLLER } & \text { relative leaf lesion expansion rate } \\ \text { SRER } & \text { stem rot expansion rate } \\ \text { RSRER } & \text { relative stem rot expansion rate } \\ \text { dpi } & \text { days post-inoculation } \\ \text { QTL } & \text { Quantitative Trait Locus }\end{array}$

\section{Introduction}

Botrytis cinerea is a necrotrophic plant pathogenic fungus that can infect at least 235 host species (Jarvis, 1977). The pathogen can cause spots, rot and blight in the field as well as in greenhouses. Furthermore, it is renowned as post-harvest pathogen on many harvested commodities (Elad, Williamson, Tudzynski, \& Delen, 2004). Infected plant tissues initially produce a white mycelium on which grey conidia develop, hence the common name of diseases caused by $B$. cinerea: grey mould. Cultivated tomato (recently renamed from Lycopersicon esculentum into Solanum lycopersicum, Spooner, Peralta, \& Knapp, 2005) is one of its economically important hosts, however, tomato breeding lines are generally considered to lack variation for resistance levels. In commercial tomato cultivation, grey mould predominantly occurs on stems after pruning of side shoots. Tomato fruit may display symptoms of primary, non-expanding lesions referred to as ghost spot (Verhoeff, 1970).

The interaction of $B$. cinerea with tomato has been thoroughly investigated (Benito, ten Have, van't Klooster, \& van Kan, 1998; Diaz, ten Have, \& van Kan, 2002; Rijkenberg, de Leeuw, \& Verhoeff, 1980; ten Have, Mulder, Visser, \& and van Kan, 1998). A number of studies indicate that the species $S$. lycopersicum may possess a (low) level of quantitative resistance to $B$. cinerea. Droplet inoculation of tomato leaves results in a rapid development (16-24 HPI) of necrotic spots at the inoculation site, but infection is temporarily restricted at this point for approximately $48 \mathrm{~h}$. From that moment onwards a proportion of the primary lesions start to expand, leading to an increase in fungal biomass and colonization of the entire leaflet in the following $48 \mathrm{~h}$ (Benito et al., 1998). The partial resistance mechanisms that mediate primary lesion containment involve phytohormone signalling pathways (Diaz et al., 2002). Ethylene, salicylic acid and jasmonic acid each individually and independently influence the proportion of aggressive, expanding lesions without affecting the lesion expansion rate, but neither of these hormones can induce full resistance (Diaz et al., 2002). Abscisic acid also influences tomato leaf resistance to $B$. cinerea (Audenaert, De Meyer, \& Höfte, 2002).

Grey mould occurs in commercial greenhouses predominantly on wound surfaces after pruning of side shoots or accidental wounding. Leaf assays may not therefore be the most representative for a greenhouse situation. Resistance to $B$. cinerea in leaves might not be functional in stems and viceversa. Dik, Koning, and Kohl (1999) previously described a stem inoculation procedure for the evaluation of biological control agents on S. lycopersicum, making use of a disease index for quantification.

Wild relatives of tomato provide a rich source of quantitative resistances to pests and pathogens (Fernandez-Munoz, Domínguez, \& Cuartero, 2000; Huang, Hoefs-van de Putte, Haanstra-van der Meer, Meijer-Dekens, \& Lindhout, 2000; Pico, Sifres, Elia, Diez, \& Nuez, 2000; Rosello et al., 1999). Quantitative resistance to B. cinerea in wild relatives of $S$. lycopersicum was reported in infection assays using leaves inoculated with mycelium grown on agar plugs (Urbasch, 1986). The differences in susceptibility between accessions were described in qualitative terms by Urbasch (1986) but the resistance levels may have been underestimated due to the very favourable conditions for fungal growth, resulting from the excess of nutrients in the agar. More recently, a number of Solanum accessions were tested for resistance to $B$. cinerea in quantitative disease assays on leaves (Guimaraes, Chetelat, \& Stotz, 2004; Nicot et al., 2002) or stems (Nicot et al., 2002) inoculated with conidial suspensions. 
Here we describe the development of a quantitative disease assay for $B$. cinerea infection on tomato stem segments and the screening of a collection of wild tomato relatives for resistance to grey mould in leaves and stem segments.

\section{Materials and methods}

\section{Plants}

Plant accessions tested are listed in Table 1. These accessions were present in public seed libraries, or obtained from De Ruiter Seeds (Bergschenhoek, The Netherlands). Plants were grown in potting soil in $12 \mathrm{~cm}$ pots $(1 \mathrm{l})$ in a greenhouse with minimal temperature set at 15 or $18^{\circ} \mathrm{C}$. Additional sodium light was applied (16 h day) in winter, from October to March. At 5-7 days after germination, $10 \mathrm{ml} \mathrm{FeNaEDTA} \mathrm{solution}\left(3.5 \mathrm{~g} \mathrm{l}^{-1}\right)$ was added, followed three days later by $10 \mathrm{ml}$ of micronutrient solution (0.286 $\mathrm{g} \mathrm{l}^{-1} \mathrm{H}_{3} \mathrm{BO}_{3}, 0.156 \mathrm{~g} \mathrm{l}^{-1} \mathrm{MnSO}_{4}$. $\mathrm{H}_{2} \mathrm{O}, 0.008 \mathrm{~g} \mathrm{l}^{-1} \mathrm{CuO}_{4} \cdot \mathrm{H}_{2} \mathrm{O}, 0.022 \mathrm{~g} \mathrm{l}^{-1} \mathrm{ZnSO}_{4}$, $\left.0.002 \mathrm{~g} \mathrm{l}^{-1}\left(\mathrm{NH}_{4}\right)_{6} \mathrm{Mo}_{7} \mathrm{O}_{24} \cdot 4 \mathrm{H}_{2} \mathrm{O}\right)$. From two weeks after germination, $5 \mathrm{ml}$ of nutrient solution $\left(5 \mathrm{mM} \mathrm{Ca}\left(\mathrm{NO}_{3}\right)_{2}, 5 \mathrm{mM} \mathrm{KNO}_{3}, 2 \mathrm{mM} \mathrm{MgSO}\right.$, $1 \mathrm{mM} \mathrm{KH}{ }_{2} \mathrm{PO}_{4}$ ) based on Hoagland and Arnon (1938) was added to the soil weekly. Plants were tested in infection assays before anthesis in order to eliminate effects of flowering on host physiology and resistance.

Leaf assay

Inoculum of $B$. cinerea strain B05.10 was prepared on malt agar (Oxoid) as described (Benito et al., 1998). Compound leaves with five fully stretched leaflets were detached from the stem of 6 week-old plants with a razor blade and transferred to pre-wetted floral foam (Smithers-Oasis, Grünstadt, Germany). The floral foam was

Table 1 List of Solanum accessions tested

\begin{tabular}{|c|c|c|c|c|c|}
\hline Species name $^{\mathrm{a}}$ & Accession code & Source $^{\mathrm{b}}$ & Comments & Leaf $^{c}$ & Stem $^{\mathrm{c}}$ \\
\hline Solanum lycopersicum & MM & WU & Moneymaker (susceptible reference) & + & + \\
\hline Solanum lycopersicum & $78 / 1604$ & DRS & cv. Kecksemeti Torpe & + & + \\
\hline Solanum lycopersicum & $82 / 2577$ & DRS & cv. Futuria & + & + \\
\hline Solanum lycopersicum & $83 / 2896$ & DRS & cv. Biruinca & + & - \\
\hline Solanum lycopersicum & $89 / 3695$ & DRS & X L. esculentum var. cerasiforme & - & + \\
\hline Solanum lycopersicum & $89 / 3862$ & DRS & cv. Olomoucke & + & - \\
\hline Solanum lycopersicum & $90 / 4063$ & DRS & L 4034 & + & - \\
\hline Solanum lycopersicum & $91 / 4311$ & DRS & cv. Seedathip 2 & + & + \\
\hline Solanum cheesmanii & G1.1615 & CGN & & - & + \\
\hline Solanum chilense & G1.1556 & CGN & & + & + \\
\hline Solanum chilense & G1.1558 & CGN & & + & - \\
\hline Solanum habrochaites & G1.1290 & CGN & & - & + \\
\hline Solanum habrochaites & G1.1560 & CGN & & + & + \\
\hline Solanum habrochaites & Lyc4 & IPK & & + & + \\
\hline Solanum habrochaites & T566/81 & IPK & & - & + \\
\hline Solanum lycopersicoides & $96 / 4326$ & DRS & Gbnr 90124 & + & + \\
\hline Solanum neorickii & G1.1601 & $\mathrm{CGN}$ & & + & + \\
\hline Solanum pennellii & LA.716 & TGRC & & + & - \\
\hline Solanum peruvianum & LA.2157 & TGRC & & - & + \\
\hline Solanum peruvianum & LA.2172 & TGRC & & - & + \\
\hline Solanum peruvianum & $\mathrm{T} 160 / 79$ & IPK & & - & + \\
\hline Solanum pimpinellifolium & $89 / 3793$ & DRS & & - & + \\
\hline Solanum pimpinellifolium & IZ.2 & MPIZ & & - & + \\
\hline
\end{tabular}

${ }^{a}$ Nomenclature of tomato and its wild relatives according to Spooner et al. (2005)

b DRS: De Ruiter Seeds, Bergschenhoek, The Netherlands; WU: Plantkundig Proefcentrum Wageningen, Wageningen University; CGN: Centre for Genetic Resources, Wageningen, The Netherlands; MPIZ: Max Planck Institut für Züchtungsforschung, Köln, Germany; TGRC: Tomato Genetics Resource Center, University of California Davis, USA; IPK: Institut für Pflanzengenetik und Kulturpflanzenforschung, Gatersleben, Germany

${ }^{c}+$ : Accession was tested in the particular assay; -, not tested 
placed in a Petri dish containing tap water and subsequently placed in a container with wet filter paper at the base, with the leaves placed horizontally. Six to ten droplets of inoculum $\left(2 \mu \mathrm{l}, 10^{6}\right.$ conidia $\mathrm{ml}^{-1}$ in Gamborg's B5 medium supplemented with $10 \mathrm{mM}$ glucose and $10 \mathrm{mM}$ phosphate buffer, $\mathrm{pH}$ 6.0) were carefully pipetted on the adaxial leaf surface. Containers were closed with a spray-wetted lid to obtain $100 \% \mathrm{RH}$, and subsequently incubated at $15^{\circ} \mathrm{C}$ in the dark. Lesion sizes were measured at 96, 120 and 144 HPI using a caliper. The LIF was determined by dividing the total number of leaf lesions expanding beyond the inoculation site (Supplementary Table 1B), by the total number of inoculation droplets (Supplementary Table 1A). The RLIF was defined as the LIF on a particular accession divided by the LIF in the susceptible control (S. lycopersicum cv. Moneymaker) in the same experiment $(\times 100 \%)$. LLERS were determined by calculating the increase in lesion size over a $24 \mathrm{~h}$ period, between 4 and 5 dpi (Supplementary Table 1C). Data for non-expanding lesions were omitted from the analysis. RLLER was defined as the average LLER on a particular accession divided by the average LLER in the susceptible control (S. lycopersicum cv. Moneymaker) in the same experiment $(\times 100 \%)$. A total of 13 accessions was tested (one leaf per plant) in 13 experiments over a period of 18 months, on at least 5 (G1.1558) up to 39 individual plants (83/2896) per accession.

\section{Stem assay (standardized procedure)}

Six week-old plants were used for inoculation. Leaves and the stem apex were removed, the stem was cut at $5 \mathrm{~cm}$ above the stem base and subsequently cut into equal segments of 5-6 cm. The segments were placed vertically in a grid with their base on wet filter paper, in a container. Prior to inoculation, the stem segments were sprayed with tap water in order to ensure equal distribution of the inoculum droplet over the wound surface. Inoculum was prepared as described for the leaf assay, but the stem segments were inoculated on top with a single droplet of $5 \mu \mathrm{l}$ $\left(10^{6}\right.$ conidia $\mathrm{ml}^{-1}$ in Gamborg's B5 medium supplemented with $10 \mathrm{mM}$ glucose and $10 \mathrm{mM}$ phosphate buffer, $\mathrm{pH}$ 6.0). Containers were closed with a spray-wetted lid to obtain 100\% $\mathrm{RH}$ and subsequently incubated at $20^{\circ} \mathrm{C}$ in the dark. Progress of the infection was analysed at 96, 120 and 144 HPI by measuring the maximum advance of stem rot symptoms at the periphery using a caliper.

SIF was determined by dividing the total number of stem segments showing stem rot symptoms expanding beyond the inoculation site (Supplementary Table 2B), by the total number of inoculated stem segments (Supplementary Table 2A). RSIF was defined as the SIF on a particular accession divided by the SIF in the susceptible control (S. lycopersicum cv. Moneymaker) in the same experiment $(\times 100 \%)$. SRERs were determined by calculating the increase in lesion size over a $24 \mathrm{~h}$ period, between 4 and 5 dpi (Supplementary Table 2C). Data for non-expanding lesions were omitted from the analysis. RSRER was defined as the average SRER on a particular accession divided by the average SRER in the susceptible control (S. lycopersicum cv. Moneymaker) in the same experiment $(\times 100 \%)$. A total of 16 accessions was tested in nine experiments, over a 10-month period, for both disease parameters on at least 44 (LA2172) up to 206 stem segments (89/3695) per accession.

Statistical analysis

All statistical analyses were performed using SPSS 12. To correct for differences between experiments, the data for all accessions were related to the control cv. Moneymaker and hence relative values are presented throughout this study. Statistical analyses were only performed for accessions with replicated data over two or more independent experiments. Statistical analyses consisted of weighted linear regressions in which 'accession' was fitted as the main explanatory variable and the number of experimental units per accession involved in the measurements as a weighing factor. Other explanatory factors like 'measurement week', were introduced in the model, but only retained in the final analysis if they explained a significant fraction of the variance. 
Initial exploratory analyses were performed using boxplots. These indicated differences among groups of accessions. To quantify differences and to obtain homogeneous subsets of accessions, we performed Ryan-Einot-Gabriel-Welsch step-down range tests based on the $F$-statistic (REGWF test). Simple correlations between disease parameters were evaluated.

\section{Adult plant assays}

Four plants of each accession and ten plants of the control S. lycopersicum cv. Moneymaker were grown according to a randomized block design in a rockwool cultivation system in the greenhouse according to standard practice and temperature set at $20 / 18^{\circ} \mathrm{C}$ day/night. As inoculum, 50 citrus fruits with heavily sporulating $B$. cinerea (strain $\mathrm{B} 05.10)$ were randomly placed through the greenhouse. High humidity was maintained by spraying the floor twice a day with tap water and leaving doors and windows closed. At weekly intervals sideshoots were removed and the resulting pruning wounds served to facilitate natural infection by $B$. cinerea conidia from the citrus fruits. The occurrence of grey mould was monitored twice a week during a period of four weeks. In a separate experimental design, sideshoots were removed and the resulting wounds were immediately inoculated with $10 \mu$ droplets of a conidial suspension of B. cinerea strain B05.10. The progress of infection was monitored twice a week during a period of four weeks. Inoculations that resulted in heavy stem rot extending beyond the inoculation point, and culminating in degeneration of the vascular system, were considered as successful infections. Inoculations yielding symptoms that did not expand through the stem were considered as unsuccessful infections.

\section{RNA hybridization}

Stem segments infected by $B$. cinerea, were sampled at 3, 4 and $5 \mathrm{dpi}$, and dissected into two parts: a basal part appearing healthy and a top part that was clearly rotten. RNA was extracted from both segments and analysed by hybridization with specific DNA probes as described by Diaz et al. (2002), using however moderate stringency washing $(0.5 \times \mathrm{SSC}, 0.5 \%$ SDS at $\left.60^{\circ} \mathrm{C}\right)$. The probes used originated from the $B$. cinerea actin gene (Benito et al., 1998) and the tomato genes ACC oxidase ACO3 (Hamilton, Bouzayen, \& Grierson, 1991), proteinase inhibitor I (Graham, Hall, Pearce, \& Ryan, 1986), pathogenesis-related proteins PR-1, GLUAC and GLUBAS (van Kan, Joosten, Wagemakers, van den Berg-Velthuis, \& de Wit, 1992) and LeHSR203 (Hoeberichts, ten Have, \& Woltering, 2003).

\section{Results}

Quantitative assays on detached tomato leaves

A detached leaf assay was used to evaluate the resistance levels of different Solanum accessions. For each individual plant one leaf was detached and inoculated. A total of 13 accessions was tested in 13 experiments on at least 5 (S. chilense G1.1558) up to 39 leaves (S. lycopersicum 83/ 2896) per accession (see Supplementary Tables S1A-S1C). Most accessions were tested in two to four independent experiments. A large variation in LIF and LLER was observed in the susceptible control ( $S$. lycopersicum cv. Moneymaker) in different experiments (Fig. 1).

For logistic reasons it was not feasible to test all accessions under study in a single experiment in the same period, thus complicating quantitative comparison between accessions. We therefore determined RLIF and RLLER, as related to $S$. lycopersicum cv. Moneymaker, in order to correct for differences between experiments performed in different weeks (Table 2). Six accessions ( $S$. lycopersicum accessions 78/1604 and 91/4311, S. lycopersicoides 96/4326, S. chilense G1.1556, S. habrochaites G1.1560 and S. neorickii G1.1601) showed a significantly lower mean weighted RLIF than the reference (Table 2). Three accessions (S. lycopersicum 91/4311, S. chilense G1.1556 and S. neorickii G1.1601) showed a significantly lower RLLER, whereas S. lycopersicoides 96/ 4326 showed a significantly higher RLLER than the reference (Table 2). 

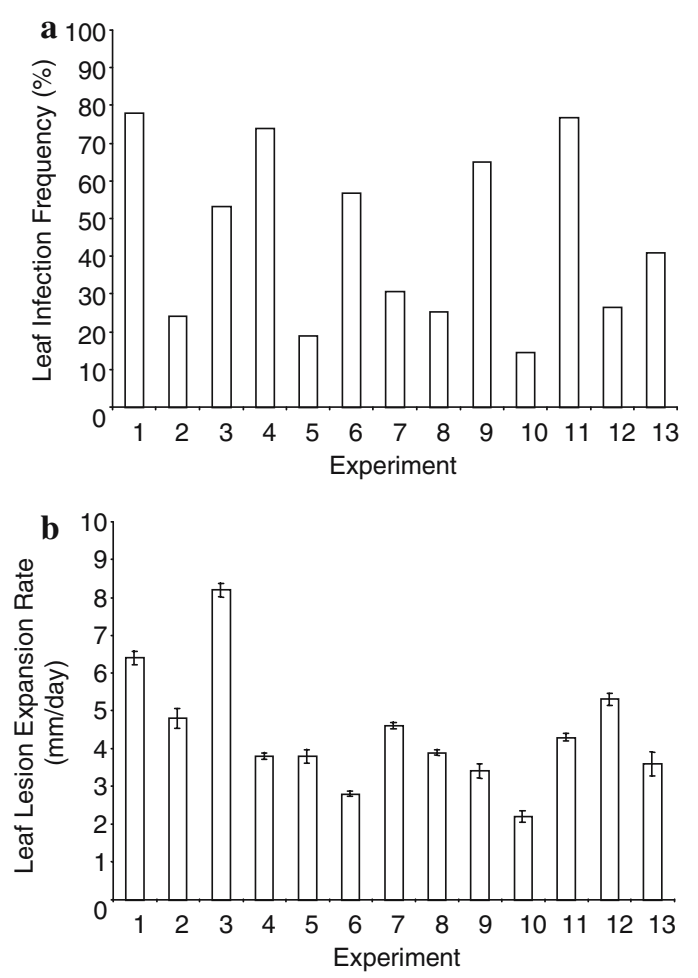

Fig. 1 Variation in leaf infection on S. lycopersicum cv. Moneymaker. (a) LIF in 13 independent experiments (in $\%$ ). (b) LLER in 13 independent experiments in $\mathrm{mm} \mathrm{day}^{-1}$. The error bar indicates the SEM

Development of standard stem segment inoculation procedure for S. lycopersicum

We intended to design a reproducible and discriminative stem inoculation procedure that should be suited for larger numbers of samples and that should yield quantitative data on infection frequency and SRER. Plants of the susceptible control (S. lycopersicum cv. Moneymaker) were used for optimising the stem segment assay. First, we evaluated the differences in disease parameters between several stem segments depending on the position in the stem (Fig. 2). Stem segments from the base as well as from the apex consistently showed a slower disease progress then the central stem segments. No difference in infection frequency or stem lesion length was observed between segments cut at the nodes or at the internodes, except for segments originating from the plant apex (Fig. 2). The effect of plant age on resistance was also tested. Plants ranging in age between four and seven weeks old were cut into eight segments of equal length and tested for resistance levels (Fig. 3). Four week-old plants showed the highest susceptibility in the apical segments. At 120 HPI the three top stem segments were fully macerated. The standard error of means was high when using stem segments derived from four week-old plants, hence such plants do not provide good material for reproducible assays. Five to seven week-old plants showed a more consistent infection.

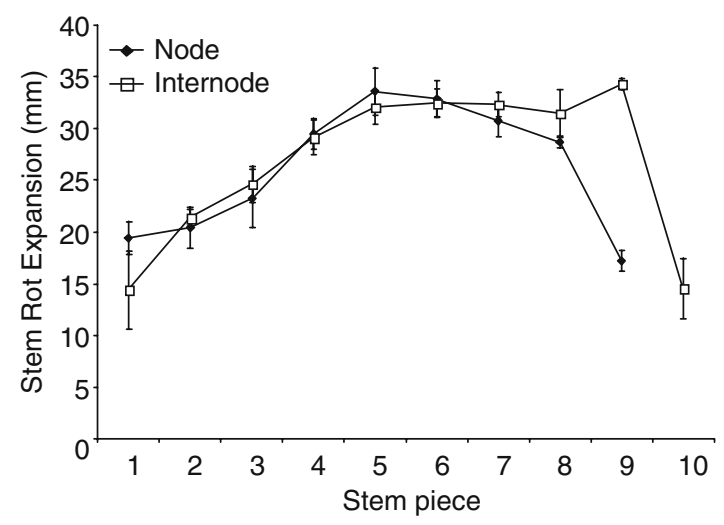

Fig. 2 Stem lesion length after inoculation at or in between the nodes. The stems of five plants were cut at the nodes or in the middle of the internodes and inoculated with a conidial suspension. At 120 HPI the rot at the stem periphery was measured. Error bars indicate the SEM

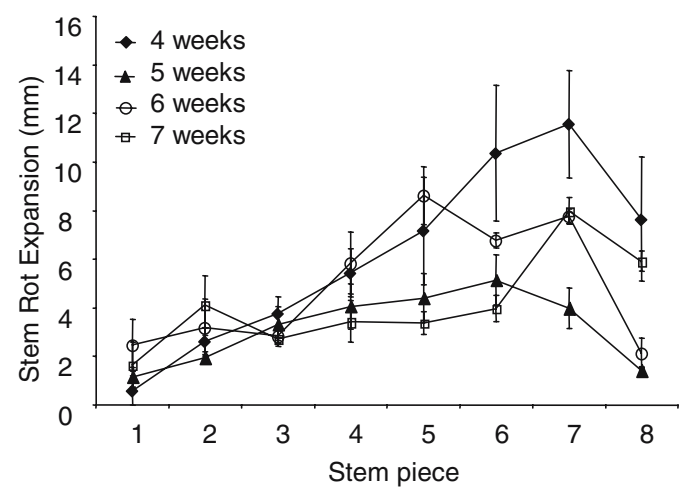

Fig. 3 Stem lesion length in inoculated segments from 4 to 7 week-old plants. The stems of four plants were cut into eight equally sized (per plant) pieces and inoculated with a conidial suspension. At 96 HPI the visual rot at the stem periphery was measured. Error bars indicate the SEM 


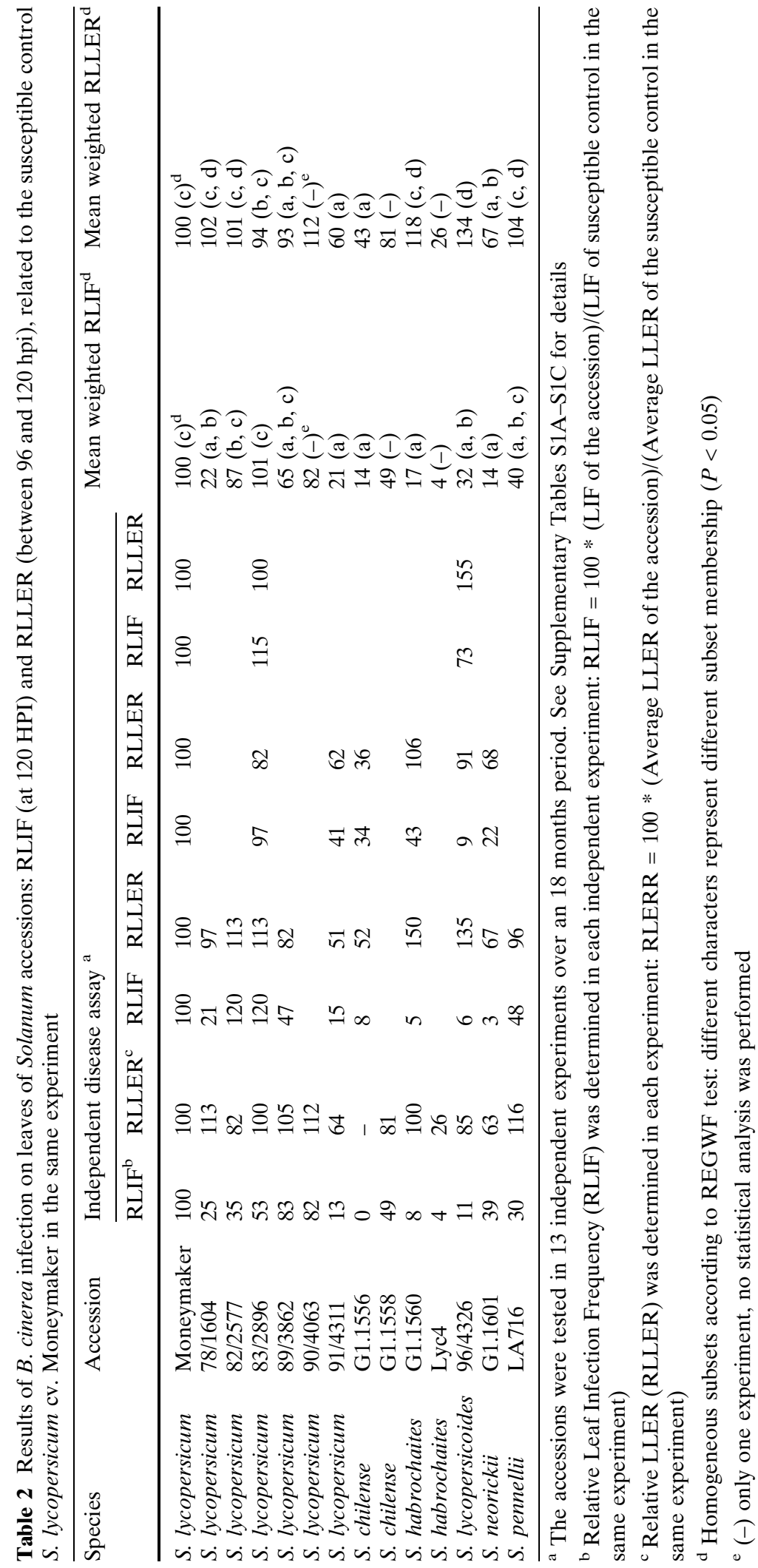


Expression of tomato defence genes in infected stem segments

Defence pathways regulated by salicylic acid, ethylene and jasmonic acid are induced in $B$. cinerea-infected tomato leaves (Diaz et al., 2002). Gene expression studies were performed to study whether these pathways are also activated in B. cinerea-infected tomato stem segments, using probes considered to be markers for the activation of different phytohormone-mediated defence pathways (van Kan, Cozijnsen, Danhash, \& de Wit, 1995): the ethylene-responsive ACC oxidase gene LeACO3, a salicylic acid-responsive PR1 gene and the jasmonate- and systeminresponsive Proteinase Inhibitor I gene. Stem segments of $S$. lycopersicum cv. Moneymaker infected by $B$. cinerea were sampled at different times and dissected in a basal part, appearing healthy, and a top part that was clearly rotten. RNA was extracted from both segments and analysed by hybridization (Fig. 4). B. cinerea actin mRNA was readily detected in the rotten part of the stem segment at $3 \mathrm{dpi}$, when the first rot symptoms were evident, and its levels increased over the next two days (Fig. 4). Transcripts of ACC oxidase (an ethylene-responsive gene) and PR1 (a salicylic acid-responsive gene) were detected both in the base and in the top of the infected stem segment, whereas Proteinase Inhibitor I mRNA was only detected in the rotten

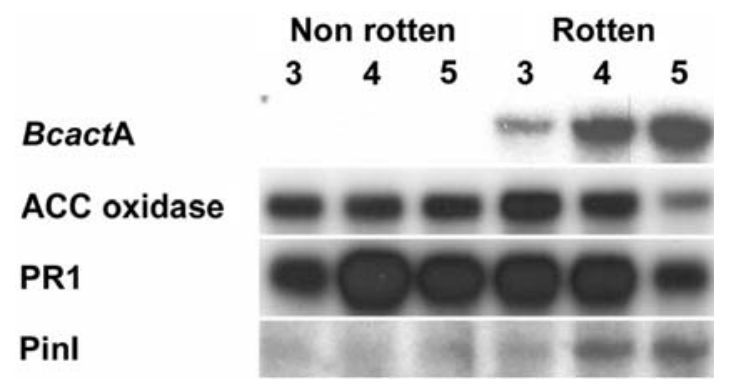

Fig. 4 RNA blot of infected stem segments of S. lycopersicum cv. Moneymaker. Stem segments of tomato cv. Moneymaker were inoculated with conidia of $B$. cinerea and incubated. RNA was extracted from rotten and non-rotten parts at 3, 4 or 5 days post-inoculation and hybridized with the indicated probes: Bcact $\mathrm{A}=$ B . cinerea actin; $\mathrm{ACC}$ oxidase = tomato ACO3 (ethylene-responsive); PR1 = tomato PR1b (salicylic acid-responsive); PinI $=$ tomato Proteinase Inhibitor I (jasmonic acid-responsive) top segment but not in the apparently healthy basal segment (Fig. 4). Uninoculated stem tissue did not show detectable transcript with either probe (not shown).

B. cinerea symptoms on stem segments of different Solanum species

Based on the pilot experiments with S. lycopersicum cv. Moneymaker, we used plants of around six weeks old for stem segment inoculation. Since lesion sizes at 120 HPI could extend up to $4 \mathrm{~cm}$ (Fig. 2), stem segments of 5-6 cm were taken from the central part of the plant. Differences in disease symptoms were observed among the accessions tested. The $S$. habrochaites and $S$. chilense accessions tested had quite woody stems and $B$. cinerea infection largely occurred on the inside of the stems. In contrast, all $S$. lycopersicum accessions showed homogeneous infection of $B$. cinerea throughout the stem. At 144 HPI, several infected stem pieces were dissected for more thorough examination. First, we verified that the advance of the rot inside the woody stem segments was in agreement with the measurement based on rot symptoms at the stem periphery. Second, cotton blue and lactophenol staining showed that mycelium was never detected beyond the macroscopically visible infection front. We conclude that latent, symptomless infection does not occur in tomato stem segments. Measuring rot on the stem segment periphery therefore served as a satisfactory quantitative marker of disease progress.

Quantitative resistance assays on stem segments of different Solanum accessions

A total of 16 accessions was tested in nine experiments for both disease parameters on at least 44 (S. peruvianum LA2172) up to 206 stem segments (S. lycopersicum 89/3695) per accession. SIF and SRER were monitored daily. The SIF on the susceptible control S. lycopersicum cv. Moneymaker over all the experiments ranged from 52 to $95 \%$, with an average of $83 \%$, while the SRER ranged from 5.4 to $9.2 \mathrm{~mm} \mathrm{day}^{-1}$ (Fig. 5).

To correct for variation between experiments, RSIF and RSRER between 96 and $120 \mathrm{HPI}$ were determined for each accession (Table 3). 

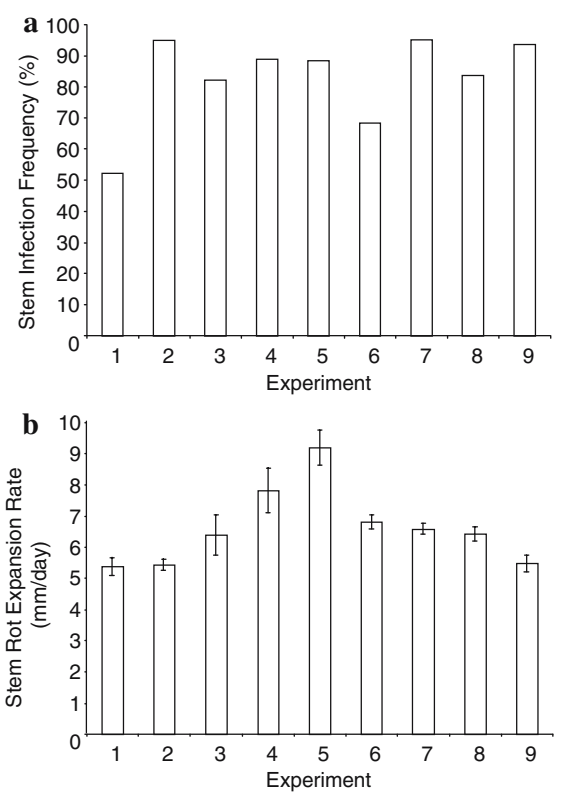

Fig. 5 Variation in stem segment infection of S. lycopersicum cv. Moneymaker. (a) SIF in nine independent experiments (in \%). (b) SRER in nine independent experiments in $\mathrm{mm} \mathrm{day}^{-1}$. The error bar indicates the SEM
S. habrochaites G1.1560 displayed a mean weighted RSIF significantly lower than the susceptible control $(P=0.001)$, whereas $S$. lycopersicum 82/2577 showed a higher mean weighted RSIF $(P=0.03)$. Four accessions (S. pimpinellifolium 89/3793, S. habrochaites accessions G1.1290 and T566/81, and S. neorickii G1.1601) showed a significantly lower mean weighted RSRER than that of the susceptible control (Table 3).

\section{Adult plant assays}

Grey mould resistance of the accessions was so far only tested on detached tissues. However, the ultimate test should be done in practical tomato cultivation in the greenhouse. Therefore, qualitative assays were performed on adult plants of a selection of accessions, grown in a greenhouse. In the first experiment, we attempted to achieve natural infection by placing profusely sporulating citrus fruit in the greenhouse and generating pruning wounds at several time points as gate-

Table 3 Results of B. cinerea infection on stem segments of Solanum accessions: RSIF (at 120 HPI) and RSRER (between 96 and $120 \mathrm{hpi}$ ), related to the susceptible control S. lycopersicum cv. Moneymaker in the same experiment

\begin{tabular}{|c|c|c|c|c|c|c|c|}
\hline \multirow[t]{2}{*}{ Species } & \multirow[t]{2}{*}{ Accession } & \multicolumn{4}{|c|}{ Independent disease assay ${ }^{\mathrm{a}}$} & \multirow{2}{*}{$\begin{array}{l}\text { Mean weighted } \\
\text { RSIF }^{\mathrm{a}}\end{array}$} & \multirow{2}{*}{$\begin{array}{l}\text { Mean weighted } \\
\text { RSRER }^{\mathrm{b}}\end{array}$} \\
\hline & & $\mathrm{RSIF}^{\mathrm{b}}$ & RSRER $^{\mathrm{c}}$ & RSIF & RSRER & & \\
\hline S. lycopersicum & Moneymaker & 100 & 100 & 100 & 100 & $100(b, c)^{d}$ & $100(b, c)^{d}$ \\
\hline S. lycopersicum & $78 / 1604$ & 77 & 118 & 93 & 102 & $85(a, b, c)$ & $111(b, c)$ \\
\hline S. lycopersicum & $82 / 2577$ & 163 & 121 & 142 & 85 & $153(d)$ & $103(b, c)$ \\
\hline S. lycopersicum & $89 / 3695$ & 160 & 109 & 102 & 83 & $129(\mathrm{c}, \mathrm{d})$ & $95(\mathrm{a}, \mathrm{b}, \mathrm{c})$ \\
\hline S. lycopersicum & $91 / 4311$ & 61 & 81 & & & $61(-)^{e}$ & $81(-)^{\mathrm{e}}$ \\
\hline S. cheesmanii & G1.1615 & 60 & 80 & 107 & 78 & $85(\mathrm{a}, \mathrm{b}, \mathrm{c})$ & $79(\mathrm{a}, \mathrm{b}, \mathrm{c})$ \\
\hline S. chilense & G1.1556 & 33 & 47 & 60 & 90 & $46(\mathrm{a}, \mathrm{b})$ & $68(\mathrm{a}, \mathrm{b}, \mathrm{c})$ \\
\hline S. habrochaites & G1.1290 & 22 & 38 & 81 & 59 & $50(\mathrm{a}, \mathrm{b})$ & 48 (a) \\
\hline S. habrochaites & G1.1560 & 30 & 51 & 8 & 108 & 22 (a) & $72(a, b, c)$ \\
\hline S. habrochaites & Lyc4 & 62 & 51 & 31 & 108 & $44(\mathrm{a}, \mathrm{b})$ & $59(\mathrm{a}, \mathrm{b})$ \\
\hline S. habrochaites & T566/81 & 54 & 52 & 39 & 35 & $58(\mathrm{a}, \mathrm{b})$ & 45 (a) \\
\hline S. lycopersicoides & $96 / 4326$ & 95 & 144 & & & $95(-)$ & $144(-)$ \\
\hline S. neorickii & G1.1601 & 97 & 59 & 43 & 34 & $76(\mathrm{a}, \mathrm{b}, \mathrm{c})$ & 49 (a) \\
\hline S. peruvianum & LA2157 & 18 & 106 & 103 & 156 & $63(a, b)$ & $132(\mathrm{c})$ \\
\hline S. peruvianum & LA2172 & 46 & 85 & & & $46(-)$ & $95(-)$ \\
\hline S. pimpinellifolium & $89 / 3793$ & 68 & 42 & 61 & 62 & $64(a, b, c)$ & 52 (a) \\
\hline S. pimpinellifolium & IZ2 & 87 & 58 & & & $87(-)$ & $58(-)$ \\
\hline
\end{tabular}

${ }^{a}$ The accessions were tested in 9 independent experiments over a 12 months period. See Supplementary Tables S2A-S2C for details

${ }^{\mathrm{b}}$ Relative Stem Infection Frequency (RSIF) was determined in each independent experiment: RSIF $=100 *$ (SIF of the accession) $/(\mathrm{SIF}$ of susceptible control in the same experiment)

${ }^{\mathrm{c}}$ Relative SRER (RSRER) was determined in each experiment: RSRER $=100 *$ (Average SRER of the accession)/(Average SRER of the susceptible control in the same experiment)

${ }^{\mathrm{d}}$ Homogeneous subsets according to REGWF test: different characters represent different subset membership $(P<0.05)$

e (-)only one experiment, no statistical analysis was performed 
ways for the infection. The control $S$. lycopersicum cv. Moneymaker was readily infected, while only very few primary disease symptoms were observed at all in the wild Solanum accessions (data not shown).

As there was some doubt about the disease pressure in the first experiment, a second experiment was performed with artificial inoculation on pruning wounds. The inoculated wound surface and surrounding stem tissue developed primary necrotic lesions $72 \mathrm{HPI}$. The $S$. lycopersicum accessions, except for 78/1604 and 91/4311, as well as $S$. lycopersicoides $96 / 4326$ became readily infected beyond the wound site where the inoculum was applied, leading to invasion and degeneration of vascular tissue and finally culminating in plant collapse. Primary necrotic lesions in the wild Solanum accessions tested did not extend beyond the site of inoculation (Table 4). Two weeks post-inoculation, plants that displayed no symptoms beyond the inoculation site were analysed in further detail. A transverse cut was made at the site of inoculation to examine fungal ingress. Some of the necrotic areas had not expanded into the main stem. In other cases the necrotic area had expanded, but it never covered more than $30 \%$ of the transverse surface of the stem.
Expression of defence-related genes

in B. cinerea-infected Solanum accessions

Gene expression was studied in a subset of Solanum accessions, representing different species and different resistance levels in leaves and/or stems (Table 5). Besides the probes used for the gene expression analysis shown in Fig. 3, three additional probes were used derived from the ethylene-responsive intracellular glucanase I, the salicylate-responsive extracelluar glucanase II (van Kan et al., 1995) and the LeHSR203 gene, which serves as marker for programmed cell death (Hoeberichts et al., 2003). Results of the hybridizations are shown in Fig. 6. BcactA and tomato ACC oxidase mRNAs showed similar expression in wild Solanum accessions as in S. lycopersicum cv. Moneymaker (see Fig. 4), however, PR1 mRNA was not detected in any of the tested B. cinerea-infected Solanum accessions. Extracellular glucanase II mRNA was detected at low levels in all accessions, whereas Glucanase I mRNA levels were high in all accessions tested. Proteinase Inhibitor 1 mRNA was not detected in any sample (not shown). LeHSR203 mRNA, a marker transcript for programmed cell death, is induced in $B$. cinerea-infected tomato leaves (Hoeberichts et al., 2003), and it was also detected

Table 4 Qualitative disease assay on adult plants grown in a greenhouse

\begin{tabular}{|c|c|c|c|c|c|}
\hline Species & Accession & No. of plants & $\begin{array}{l}\text { No. of inoculation } \\
\text { sites }^{\text {a }}\end{array}$ & Successful infections $^{b}$ & Infection frequency $^{c}$ \\
\hline S. lycopersicum & Moneymaker & 10 & 29 & 15 & 52 \\
\hline S. lycopersicum & $78 / 1604$ & 3 & 8 & 0 & 0 \\
\hline S. lycopersicum & $82 / 2577$ & 4 & 10 & 7 & 70 \\
\hline S. lycopersicum & $83 / 2896$ & 4 & 11 & 7 & 64 \\
\hline S. lycopersicum & $89 / 3862$ & 3 & 8 & 6 & 75 \\
\hline S. lycopersicum & $91 / 4311$ & 3 & 8 & 0 & 0 \\
\hline S. chilense & G1.1558 & 3 & 9 & 0 & 0 \\
\hline S. habrochaites & G1.1290 & 3 & 9 & 0 & 0 \\
\hline S. habrochaites & G1.1560 & 3 & 9 & 0 & 0 \\
\hline S. habrochaites & Lyc4 & 3 & 9 & 0 & 0 \\
\hline S. habrochaites & T566/81 & 2 & 6 & 0 & 0 \\
\hline S. lycopersicoides & $96 / 4326$ & 2 & 4 & 2 & 50 \\
\hline S. neorickii & G1.1601 & 3 & 9 & 0 & 0 \\
\hline
\end{tabular}

\footnotetext{
${ }^{a}$ Adult plants were inoculated with $B$. cinerea at pruning wound sites

$\mathrm{b}$ The number of inoculations resulting in expanding lesion and invasion of vascular tissue

${ }^{c}$ The proportion of inoculations leading to successful infection $(\times 100 \%)$
} 
Table 5 Resistance level of accessions used in gene expression studies

\begin{tabular}{|c|c|c|c|c|c|}
\hline Species (accession) ${ }^{\mathrm{a}}$ & RLIF & RLLER & RSIF & RSRER & Lane \\
\hline S. peruvianum (LA2172) & - & - & 46 & 85 & 1 \\
\hline S. chilense (G1.1556) & $14^{*}$ & $43^{*}$ & 46 & 68 & 2 \\
\hline S. pimpinellifolium $(89 / 3793)$ & - & - & 64 & $52 *$ & 3 \\
\hline S. neorickii (G1.1601) & $14 *$ & $67 *$ & 76 & $49 *$ & 4 \\
\hline S. chilense (G1.1558) & 49 & 81 & - & - & 5 \\
\hline S. cheesmanii (G1.1615) & - & - & 85 & 79 & 6 \\
\hline
\end{tabular}

Data are taken from Tables 2 and 3. Disease parameters that are significantly different from the control S. lycopersicum cv. Moneymaker are marked with an asterisk

${ }^{\text {a }}$ For abbreviations, see Tables 2 and 3

in some of the Solanum accessions tested. No hybridization was detected in non-inoculated stems of the accessions tested using any probe (not shown).

\section{Discussion}

Quantitative disease assays were applied for evaluating partial resistance to $B$. cinerea in wild relatives of cultured tomato, both in leaves and stem segments. In both tissues two separate parameters for resistance were determined, i.e. the proportion of inoculation sites that led to successful disease outgrowth (infection fre- quency) and the speed of disease outgrowth over a $24 \mathrm{~h}$ timespan (expansion rate). The detached leaf assays were prone to several experimental limitations that hampered robust quantitative analysis. There were obvious physiological differences between the Solanum species tested. All plants were cultivated in the same greenhouse compartment under the same conditions, which were optimal for $S$. lycopersicum cv. Moneymaker, a tomato cultivar typically suited for cultivation in a greenhouse. Leaves of several wild Solanum species did not tolerate the high humidity that is essential for $B$. cinerea infection assays (Williamson, 1994). These leaves developed bleached spots which turned into a callus-

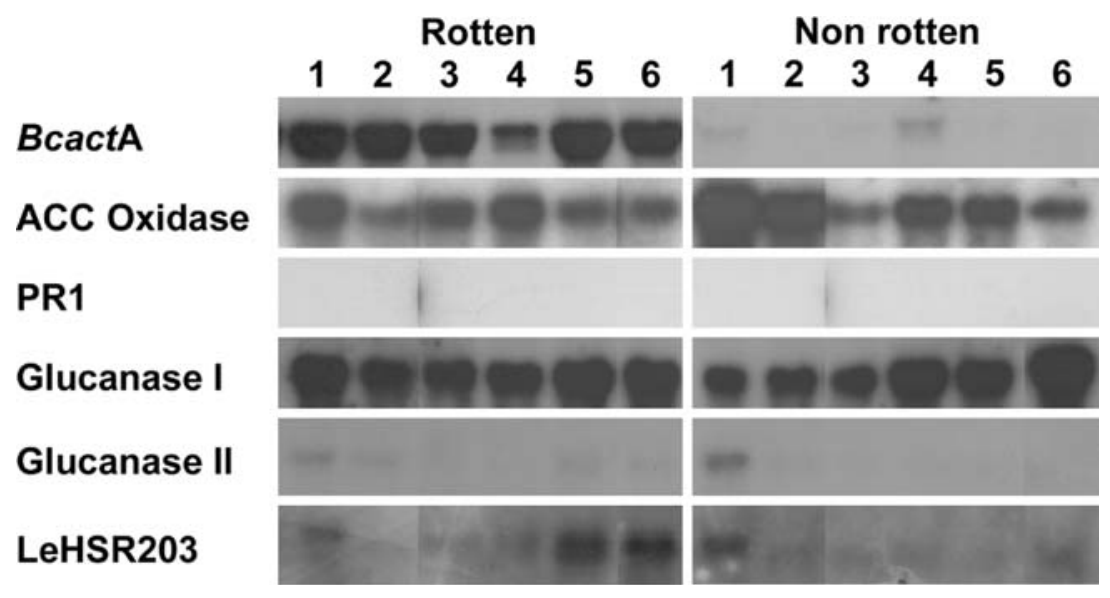

Fig. 6 RNA blot of infected stem segments of different Solanum accessions. Stem segments of Solanum accessions with different levels of partial leaf or stem resistance (see Table 5) were inoculated with conidia of $B$. cinerea and incubated. RNA was extracted from rotten and non-rotten parts at 5 days post-inoculation. Lanes 1-6 contain RNAs from the following accessions: 1: LA2172; 2: G1.1556; 3:
89/3793; 4: G1.1601; 5: G1.1558; 6: G1.1615. The blots were hybridized with the indicated probes: Bcact $\mathrm{A}=B$. cinerea actin; ACC oxidase $=$ tomato ACO3; PR1 = tomato PR1b (PR-P6); Glucanase I = basic, vacuolar $\beta$-1,3-glucanase GLUBAS; Glucanase II = acidic, extracellular $\beta$-1,3-glucanase GLUAC; LeHSR203 = tomato hsr203J homolog, a marker gene for programmed cell death 
like oedema and completely disintegrated, as also previously reported (Moreau et al., 1997; Nicot et al., 2002). The standard deviation within a leaf inoculation experiment was usually small but large differences were observed between experiments for some accessions. In the susceptible control, S. lycopersicum cv. Moneymaker, both the LIF and the LLER were found to vary fourfold between experiments. Attempts to minimize such variation were unsuccessful. Inoculation was also performed on leaves attached to the plant in humid plastic tents put up in greenhouses, or in growth cabinets set at $96 \% \mathrm{RH}$, but the results were not sufficiently reproducible (data not shown). The stem assay appeared to be more robust in terms of reproducibility between experiments performed in different seasons. Even though the number of data points in stem segment assays (5-10 per individual plant) was smaller than in the leaf assays (40 per individual plant), variation between experiments in the stem segment assays was less than two-fold for both disease parameters (compare Figs. 1 and 5).

Six accessions showed significantly reduced LIF, three of which (S. lycopersicum 91/4311, S. chilense G1.1556 and S. neorickii G1.1601) also showed a significantly lower LLER, while the other three only showed resistance for a single parameter (Table 2). There were also differences among accessions in SIF (Table 3). However, the smaller number of observations (one inoculation per stem segment, as compared to 40 inoculations per leaf) affected the statistical significance. Only S. habrochaites G1.1560 was significantly more resistant in the stem segment assay with respect to the SIF. This accession was also reported by Nicot et al. (2002) to be more resistant. The three accessions that were resistant for both disease parameters in the leaf assay (S. lycopersicum 91/ 4311, S. chilense $\mathrm{G} 1.1556$ and $S$. neorickii G1.1601) also showed a lower RSIF than the control, but the differences were not significant (Table 3). None of the accessions tested in the stem segment assay was significantly more resistant for both disease parameters.

A correlation was observed between the infection frequencies on leaves and stem segments $(r=0.78 ; n=8)$, as well as for the lesion expansion rates on leaves and stems $(r=0.70 ; n=8)$.
There was, however, only a very poor correlation between infection frequency and expansion rates on leaves $(r=0.28 ; n=11)$ or stem segments $(r=0.42 ; n=19)$.

Traits affecting the infection frequency or disease expansion rate might be based on independent mechanisms and could involve distinct loci in the genome. Moreover, resistance to $B$. cinerea in leaves may involve mechanisms and genetic loci distinct from those conferring resistance in stems. Several accessions were identified with an IF significantly lower than in the control, yet the leaf lesions or stem rot that expanded did so at similar rate (e.g. S. lycopersicum 78/1604). The converse was not found: no accessions displayed an IF comparable to that of S. lycopersicum cv. Moneymaker but a slower disease growth rate than the control. Thus the genetic traits may not contribute equally to either resistance parameter.

It is tempting to consider the IF parameter as the most important and attractive to be applied in resistance screening programmes, because it is easier to determine experimentally. However, some accessions with a low RLIF displayed a disease expansion rate that was higher than the control (e.g. in leaves and stems of S. lycopersicoides 96/4326), which may eventually lead to faster and heavier sporulation, thereby causing the outbreak of a grey mould epidemic. We propose that determination of the disease expansion rate on either leaf or stem, although more laborious, has an added value for evaluating resistance levels.

Guimarães et al. (2004) observed that a resistant $S$. lycopersicoides accession caused the death and degeneration of GFP-expressing $B$. cinerea hyphae in the infected tissue, resulting in loss of GFP fluorescence. We did not examine resistant accessions described here for hyphal degeneration in a similar way, because the GFP-expressing B. cinerea strain used by Guimarães et al. (2004) was poorly virulent under our experimental conditions, even on the susceptible S. lycopersicum cv. Moneymaker (ten Have, unpublished results).

The expression of several genes was monitored considered to be representative for defence responses mediated by signalling pathways that involve either ethylene (type I $\beta$-1,3-glucanase), 
jasmonate (proteinase inhibitor I) or salicylate (PR1, type II $\beta$-1,3-glucanase), which all contribute to partial resistance in cultivated tomato, S. lycopersicum (Diaz et al., 2002). We investigated whether one or more defence pathways were constitutively activated or induced to higher levels in a subset of accessions, representing multiple Solanum species and displaying a spectrum of partial resistance levels. Resistance levels in the wild accessions analysed for gene expression did not correlate with the expression of salicylateinducible PR proteins (PR1, type II $\beta$-1,3-glucanase). Expression of PR1 mRNA was detected only in S. lycopersicum (Fig. 4) but not in the other Solanum species tested (Fig. 6), even though the probes and experimental conditions used were appropriate to detect hybridization to genomic DNA in these species (not shown). It was previously reported that PR proteins do not contribute in resistance mechanisms of tomato leaves to $B$. cinerea (Diaz et al., 2002). Ethylene production was induced in all accessions tested as evidenced by the increase in transcript levels of ACC oxidase (Figs. 4 and 6), leading to induction of ethyleneresponsive genes such as the intracellular type I $\beta$-1,3-glucanase-encoding gene (Fig. 6).

In potato cultivars differing in partial (race non-specific) resistance to the late blight pathogen Phytophthora infestans, a correlation was observed between constitutive expression of PRprotein encoding genes and the level of partial resistance (Vleeshouwers, van Dooijeweert, Govers, Kamoun, \& Colon, 2000). Also in rice, accessions showing partial resistance to the rice blast fungus Magnaporthe grisea had a higher level of endogenous salicylate and concomitantly higher expression of salicylate-induced defence genes (Silverman et al., 1995). Altogether, the expression analysis in the Solanum accessions tested did not pinpoint any particular gene whose expression pattern was possibly associated with higher levels of partial resistance to grey mould. It thus remains to be resolved which defence pathways and mechanism(s) contribute to the reduction of $B$. cinerea infection frequency and disease expansion in resistant accessions.

The availability of a reproducible quantitative assay, as well as the identification of accessions with a genetically determined (partial) grey mould resistance opens the way for resistance breeding in cultured tomato varieties. Reducing the infection frequency may slow down disease outgrowth and delay the moment of sporulation, culminating in a lower inoculum pressure in an infested greenhouse. The inoculum dosage and experimental conditions in this study were chosen such that they optimized $B$. cinerea infection. Disease pressure in commercial greenhouses is probably lower and environmental conditions are less favourable for pathogen invasion and establishment. Thus the partial resistance levels that were identified may in practice turn out to be even more promising. Wild Solanum accessions displaying a reduction of either disease parameter thus provide useful sources for introgressing two separate traits for partial resistance to grey mould into cultured tomato. Two of the accessions described here have been used for introgressing resistance into cv. Moneymaker. QTL analysis of segregating populations from these crosses will be published elsewhere.

Acknowledgements This research was sponsored by the Dutch Technology Foundation STW, applied science division of NWO and the technology programme of the Ministry of Economic Affairs (project WBI4712), and partly funded by De Ruiter Seeds, Bergschenhoek, the Netherlands. The authors are grateful to Brian Williamson for critical reading of the manuscript, to Ben van der Knaap, Marianne Sela and Paul Maris (De Ruiter Seeds) for their continuous stimulating contribution to discussions, to Maarten Peters for plant care and to Maurice van Veen for technical assistance.

\section{References}

Audenaert, K., De Meyer, G. B., \& Höfte, M. M. (2002). Abscisic acid determines basal susceptibility of tomato to Botrytis cinerea and suppresses salicylic acid-dependent signaling mechanisms. Plant Physiology, 128, 491-501.

Benito, E. P., ten Have, A., van't Klooster, J. W., \& van Kan J. A. L. (1998). Fungal and plant gene expression during sychronized infection of tomato leaves by Botrytis cinerea. European Journal of Plant Pathology, 104, 207-220.

Diaz, J., ten Have, A., \& van Kan, J. A. L. (2002). The role of ethylene and wound signaling in resistance of tomato to Botrytis cinerea. Plant Physiology, 129, 1341-1351. 
Dik, A. J., Koning, G., \& Kohl, J. (1999). Evaluation of microbial anatagonists for biological control of Botrytis cinerea stem infection in cucumber and tomato. European Journal of Plant Pathology, 105, 115-122.

Elad, Y., Williamson, B., Tudzynski, P., \& Delen, N. D. (2004). Botrytis: biology, pathology and control. Dordrecht, The Netherlands: Kluwer Academic Publishers, p. 428.

Fernandez-Munoz, R., Domínguez, E., \& Cuartero, J. (2000). A novel source of resistance to the twospotted spider mite in Lycopersicon pimpinellifolium (jusl.) mill:: Its genetics as affected by interplot interference. Euphytica, 111, 169-173.

Graham, J. S., Hall, G., Pearce, G., \& Ryan, C. A. (1986). Regulation of synthesis of proteinase inhibitors I and II mRNAs in leaves of wounded tomato plants. Planta, 169, 399-405.

Guimarães, R., Chetelat, R., \& Stotz, H. (2004). Resistance to Botrytis cinerea in Solanum lycopersicoides is dominant in hybrids with tomato, and involves induced hyphal death. European Journal of Plant Pathology, 110, 13-23.

Hamilton, A. J., Bouzayen, M., \& Grierson, D. (1991). Identification of a tomato gene for the ethyleneforming enzyme by expression in yeast. Proceedings of the National Academy of Sciences USA, 88, 7434-7437.

Hoagland, D. R., \& Arnon, D. I. (1938). The water-culture method for growing plants without soil. Agricultural Experiment Station Circular 347, pp. 1-35. Berkeley, California.

Hoeberichts, F. A., ten Have, A., \& Woltering, E. J. (2003). A tomato metacaspase gene is upregulated during programmed cell death in Botrytis cinereainfected leaves. Planta, 217, 517-522.

Huang, C. C., Hoefs-van de Putte, P. M., Haanstra-van der Meer, J. G., Meijer-Dekens, F., \& Lindhout, P. (2000). Characterization and mapping of resistance to Oidium lycopersicum in two Lycopersicon habrochaites accessions: evidence for close linkage of two Ol-genes on chromosome 6 of tomato. Heredity, 85, 511-520.

Jarvis, W. R. (1977). Botryotinia and Botrytis species: taxonomy, physiology, and pathogenicity. Monograph, Research Branch Canada Department of Agriculture: 15.

Moreau, P., Thoquet, P., Laterrot, H., Moretti, A., Olivier, J., \& Grimsley, N. H. (1997). A locus, ltm, controlling the development of intumescences, is present on chromosome 7. TGC Report, 47, 15-16.

Nicot, P. C., Moretti, A., Romiti, C., Bardin, M., Caranta, C., \& Ferrière, H. (2002). Differences in susceptibility of pruning wounds and leaves to infection by Botrytis cinerea among wild tomato accessions. TGC Report, $52,24-26$.
Pico, B., Sifres, A., Elia, M., Diez, M. J., \& Nuez, F. (2000). Searching for new resistance sources to tomato yellow leaf curl virus within a highly variable wild Lycopersicon genetic pool. Acta Physiologica Plantarum, 22, 344-350.

Rijkenberg, F. H. J., de Leeuw G. T. N., \& Verhoeff, K. (1980). Light and microscopy studies on the infection of tomato fruits by Botrytis cinerea. Canadian Journal of Botany, 58, 1394-1404.

Rosello, S., Soler, S., Diez, M. J., Rambla, J. L., Richarte, C., \& Nuez, F. (1999). New sources for high resistance of tomato to the tomato spotted wilt virus from Lycopersicon peruvianum. Plant Breeding, 118, 425-429.

Silverman, P., Seskar, M., Kanter, D., Schweizer, P., Metraux, J. P., \& Raskin, I. (1995). Salicylic acid in rice (biosynthesis, conjugation and possible role). Plant Physiology, 108, 633-639.

Spooner, D. M., Peralta, I. E., \& Knapp, S. (2005). Comparison of AFLPs with other markers for phylogenetic inference in wild tomatoes [Solanum L. section Lycopersicon (Mill.) Wettst.]. Taxon, 54, 43-61.

ten Have, A., Mulder, W., Visser, J., \& van Kan, J. A. L. (1998). The endopolygalacturonase gene Bcpg1 is required for full virulence of Botrytis cinerea. Molecular Plant-Microbe Interactions, 11, 1009-1016.

Urbasch, I. (1986). Resistenz verschiedener Kultur- und Wildtomatenpflanzen (Lycopersicon spp.) gegenüber B. cinerea Pers. Journal of Phytopathology, 116, 344351.

van Kan J. A. L., Cozijnsen A. J., Danhash N., \& de Wit, P. J. G. M. (1995). Induction of tomato stress protein mRNAs by ethephon, 2,6-dichloroisonicotinic acid and salicylate. Plant Molecular Biology, 27, 1205-1213.

van Kan, J. A. L., Joosten, M. H. A. J., Wagemakers, C. A. M., van den Berg-Velthuis G. C. M., \& de Wit P. J. G. M. (1992). Differential accumulation of mRNAs encoding extracellular and intracellular PR proteins in tomato induced by virulent and avirulent races of Cladosporium fulvum. Plant Molecular Biology, 20, 513-527.

Verhoeff, H. (1970). Spotting on tomato fruits caused by Botrytis cinerea. Netherlands Journal of Plant Pathology, 76, 219-226.

Vleeshouwers, V. G. A. A., van Dooijeweert, W., Govers, F., Kamoun, S., \& Colon, L. T. (2000). Does basal PR gene expression in Solanum species contribute to nonspecific resistance to Phytophthora infestans?. Physiological and Molecular Plant Pathology, 57, 35-42.

Williamson, B. (1994). Latency and quiescence in survival and success of fungal plant pathogens. In: J. P. Blakeman \& B. Williamson (eds.), Ecology of plant pathogens (pp. 187-207). Oxford, UK: CAB International. 